\title{
The infiltration and alienation of cyber language in Higher Vocational College Campus Culture
}

\author{
ZHANG Chaomin \\ Department of economics and trade, Guangdong Eco-engineering Polytechnic, Guangzhou 51052,China
}

Keywords: Network language; higher vocational colleges; infiltration; alienation

\begin{abstract}
Network language is the product of the rapid development of information technology. As a virtual language, network language is more concise, variable, innovative, popular, interesting or vulgar. School of higher vocational colleges is one of the main recipients of network information, network language has become the common language of them, if not handled correctly the alienation phenomenon of network language and culture, it is easy to cause a negative impact on the growth of higher vocational students in higher vocational colleges, thus strengthening the network language specification construction and monitoring mechanism, has important significance. This paper first analyzes the characteristics of the network language, and in the new period network language permeation in Higher Vocational Colleges in the culture and alienation phenomenon are analyzed, and finally puts forward the countermeasures to face up to the network language alienation, to create a harmonious campus culture.
\end{abstract}

\section{Introduction}

Information network has penetrated into all aspects of people's lives, and has a far-reaching impact on the world's economic, cultural and social development. As a network of Internet language, Internet language also happens naturally. The use of network language and society from all walks of life there are some disputes, especially the network language anomie, lead the people to the network language "turn pale at the mention of a tiger". Higher vocational college students as the younger generation, to accept new things and enthusiasm is high, so the network language has great influence on their life and behavior, how to deal with the infiltration and alienation of network language in higher vocational campus culture, and proper guidance is an important problem for educators to think about.

\section{Characteristics of network language}

Network language first refers to the computer language of the network, and also refers to the natural language that has its own characteristics on the network. With the spectrum of the network, network language has been widely spread in the field of social networking, and gradually accepted by people. The network language includes Internet terminology, network literature language, network language and network chat forums and news language, the network language is fourth for network communication, network communication and has strong color of language. Specifically, the characteristics of network language are mainly manifested in the following points.

Personalization and autonomy. Network virtual world, people social virtualization, so you can speak freely, the greatest extent to express their views, to play the freedom of interpersonal communication. With the development of network technology, more and more interpersonal communication platform appears, and BBS, forum, watercress, knowledge and so on provide the space for public discussion, and provide a new carrier for the emergence and dissemination of network language. In the virtual space, interpersonal communication has become possible prosperity, freedom of expression, so the sentence, discourse content with ghostly narrative, there is no certainty and statute of limitations, people began to pursue their own individuality in the network platform, and 
the language re combination to express individuality. Contrary to the traditional theory of linguistics and the network language, it appears mainly in the speaker's will, has a very clear attitude towards language or word pattern, such as "embarrassed" by orz in 2008 to join the China elements, was given a "sad, depressed and embarrassed" meaning, has a very clear feeling color.

Openness and inclusiveness. Openness and inclusiveness are determined by the openness and inclusiveness of the network society. The relatively loose network environment, active cultural atmosphere and free network communication provide the conditions for the development of Internet language. Internet language is an open symbolic system. Internet users often use loanwords from foreign languages and dialects to supplement and develop Chinese language, giving new definitions to Chinese characters. Incomplete statistics show that since the beginning of 90s last century, the network has increased the number of new Chinese every year 1000, and at least $50 \%$ of which are derived from network terms.

Innovation and variability. Traditional spoken or written language are subject to grammatical norms and restrictions, and pay more attention to the aesthetic and acceptability of the audience. Internet language is different. It is more open and innovative. Internet users through the Internet to contact more things, creativity is also relatively strong, can give full play to their initiative through the network platform, the greatest degree of imagination to create humorous, ingenious language network, such as "frog", "dinosaur", "rookie" and other words in the sense of variation in particular, the environment, users can understand and accept this kind of variation.

Simplicity and vividness. The traditional written language by language, format, content and other restrictions, in the process of using need through the cumbersome sentences to express or explain the meaning of simple, increased the difficulty of understanding, but in the network communication, Internet users quickly in order to express their meaning, save typing time, only the main meaning of the text will the accuracy of text extraction, ignored even, this provides the possibility for the network language's conciseness and vividness. Such as "886", "-D" and "\%>_<\%" language and symbols appear. The emergence of these languages, through the expression of the image, makes the virtual world more vivid, and adds a touch of human touch to the communication of Internet users.

Popularity and interest. With the development and popularization of network technology, people's communication basically breaks the geographical restrictions, which is incomparable to the traditional spoken language. Written language has certain requirements for the user's cultural level, so it is limited in the promotion, and the network language will not be limited by the geographical and cultural level. In the Internet world, the language environment is relatively loose, and if the new network language is loved and accepted by Internet users, it will begin to imitate and even imitate. Such as the 2011 "awesome", not only widely spread in the network world, even by the "people's Daily", the central station quoted, becoming the most inspiring words.

Vulgarity and anomie. Either oral or written language are in use of corresponding standard constraints, the network language but not by this constraint, which leads to the network language often appear typos and ambiguous phenomenon is not standardized. Some users in communication, in order to pursue the convenient and fast, do not pay attention to whether the use of standardized and accurate words, or even create arbitrary words, such as editing is called "pee", viewers called "eat melon masses" etc.. At the same time, network expressions are vulgar at the same time. This is due to the absence of network management, such as the use of vulgar language such as "TMD" and "CAO".

\section{Network language infiltration and alienation in Higher Vocational Campus Culture}

Through the observation of the campus forums and chat rooms chat, can be found in "shoes" and "Zi" and "TMD" network language alienation of students using this meet the eye everywhere, love, fresh and stimulating variation of discourse, thus showing themselves in line with the times, conform to no conventional pattern. The young students follow the trend of blind and grandstanding psychology, which makes cyber language infiltrate and alienation in the campus culture of Higher Vocational colleges. 
Network language leads to changes in students' thinking and ways of language. Young students as the main force of the Internet age, the use of mobile phone and computer network terminal equipment accounted for more than half of their life time, which makes their living space is mostly filled with network, thinking and language the way they effectively change. Higher vocational college students because of their learning ability, thinking and other aspects of the level, not willing to think for themselves when they encounter problems, and the habit of searching on the Internet, in the forums and chat rooms but seek, and the network language, the accuracy of the indiscriminate use of information is so widespread, students self identification difficult. This makes the students vulnerable to bad language in network language, which leads to a decline in the ability of Higher Vocational Students' self judgment and discernment, and even have a negative impact on students' learning ability, thinking mode and behavior ability.

Change the outlook on life and the spiritual world of Higher Vocational Students. The social network environment is complex, students need to vent or transfer of pent up emotion through the network, the network and the lack of supervision led to a variety of vulgar, violent and vulgar language and behavior with network. The network language fomo as a result of some higher vocational students chatting, subjective judgment, malicious use of violence, vulgar words, personal attacks on innocent people, become one of the main groups of network violence. This network fomo tool, and forces the dominant role of the user, and even the students outlook on life, world outlook and values of the formation of kidnapping, cause the student gradually deviate from the right path in life. In the long term of violence and alienation under the network environment, students gradually lose self-control, and gradually be vulgar, violent and vulgar language network to make, and even make the students have a radical, violent behavior, a serious violation of social security.

The alienation of Internet language can lead to the loss of students' social skills. The alienation of network language has a negative impact on the growth of higher vocational students, which leads to students' sense of existence in the virtual network and the Internet world. The network language user's cultural level, personal qualities are low, so the students on the Internet and Internet users to communicate, do not know each other's background, education, gender and age and other basic information, just indulge in the network language brings freshness and excitement, especially in recent years, the students to be friends with the quantity of partial color phenomena have occurred. As with the written language, the network language is more simple and easy to learn, but it also has a specific use of the environment, so the students to communicate in real life with the students, teachers and relatives, misunderstood, which leads to the students' interest in interpersonal loss, resulting interpersonal indifference phenomenon, is not conducive to the cultivation of students enter the society after social skills. The network language is "cynical" and "overweening" color will inevitably lead to higher vocational students' social psychology, thought and behavior of students, lead to misguided.

\section{We should deal with the infiltration and alienation of cyber language in Higher Vocational Campus Culture}

The web is full of every aspect of people's life, the network language can not be avoided, as a traditional and rebellious, history and fashion, virtual reality and cultural impact, we should not use and effect of avoidance of network language, and should face the penetration and alienation, and take effective measures to deal with.

Educators change their ideas and take the initiative to know the Internet Language. Higher vocational college students as one of the new era has become the main force, the main use of network language, the network ideological and political education workers get in by every opening, therefore, can not simply rely on the block to intercept basically no effect, and simple indoctrination in ideological education and even make students appear rebellious, play the reverse role, so educators must to change the traditional ideas, take the initiative to contact and learn the language network, not only can be closer to the daily life of students, and students can master the language habits and found the error factors in network language, to better guide the students' acute. In addition, ideological and 
political workers in Colleges and universities need to understand and master the network language system of students to adapt to their network communication, so that changes in students' thinking and behavior can be mastered in a timely manner.

Focus on hot issues, purify the network space. The school can create various forums, websites to attract students, and the specialized management of network technology, operation skill, purify the network environment and network audit using the language teachers to mingle with the students, by students in communication and exchange, to guide students to Jian Lizheng's outlook on life and values etc.. For some hot issues, we can organize students to participate actively, and realize the real educational function through purposeful guidance. Educators can through the network of pictures, text and video and other resources to carry out the campus cultural activities, organization network essay, carry forward the spirit of patriotism, to enhance the students' Ideological and political quality, so that the adverse factors can consciously take the initiative to boycott the network language.

Strengthen the students' language accomplishment education. As a first language tool for students of interpersonal communication, plays an important role in the future development of students, so the school can strengthen Chinese education, elective courses of humanities special aspects of the organization, students learn classical masterpiece, improve their humanistic quality and cultural accomplishment, to master the correct use of language, network language to deal with the problem of alienation better bring.

Strengthen the students' psychological attention and walk into the students' inner world. Higher Vocational College Students' learning ability is not due to cultural lessons, it is easy to make their sense of inferiority of interpersonal communication in the real world, and in the virtual world, they feel respected, can be more real self publicity, so obsessed with the Internet world and the network language. In view of this, vocational education should change the mental state and the real concern of the students, can set up a special chat room, encounter life and psychological problems in the students to be the correct guidance, to enable students to open their hearts, really into the inner world of the students, in order to resist the network language alienation through guiding the bad mood the effect of.

\section{Conclusion}

In short, the network language in the daily life of students, learning in penetration, vocational education should resist the alienation of network language, it must be comprehensive, timely grasp of the psychology of the students, by means of guide students outlook on life, values and world view, in the virtual world can consciously resist unhealthy temptations, the alienation of the correct language processing network.

\section{References}

[1] Zhang Xiaorong. Value and application of network language in college students' Ideological and political education [J]. Journal of Sichuan University of Science and Engineering (SOCIAL SCIENCE EDITION), 2012,27 (2): 98-102.

[2] Tang Meiying. Motivation of Internet language innovation and its improper orientation [J]. Journal of Henan Normal University: Philosophy and Social Science Edition, 2010, (4): 182.

[3] Xie Ping, Hu Yuanchao. Interpersonal communication in Ideological and political education in Colleges and universities. Based on the theory of communication analysis [J]. Journal of Nanjing University of Posts and Telecommunications: Social Science Edition, 2010, (4): 97.

[4] Zhang Huixin. Analysis of ways of applying network language to campus culture construction [J]. Journal of Hubei Radio and TV University, 2012, (12): 92.

[5] Wang Yi. Profit and loss of College Ideological and political education by network culture. [J]. Journal of Henan Normal University: Philosophy and Social Science Edition, 2012, (6): 246. 